Document downloaded from:

http://hdl.handle.net/10251/59165

This paper must be cited as:

Samper, M.D.; Arrieta, MP.; Ferrándiz Bou, S.; López Martínez, J. (2014). Influence of Biodegradable Materials in the Recycled Polystyrene. Journal of Applied Polymer Science. (131):41161-41168.

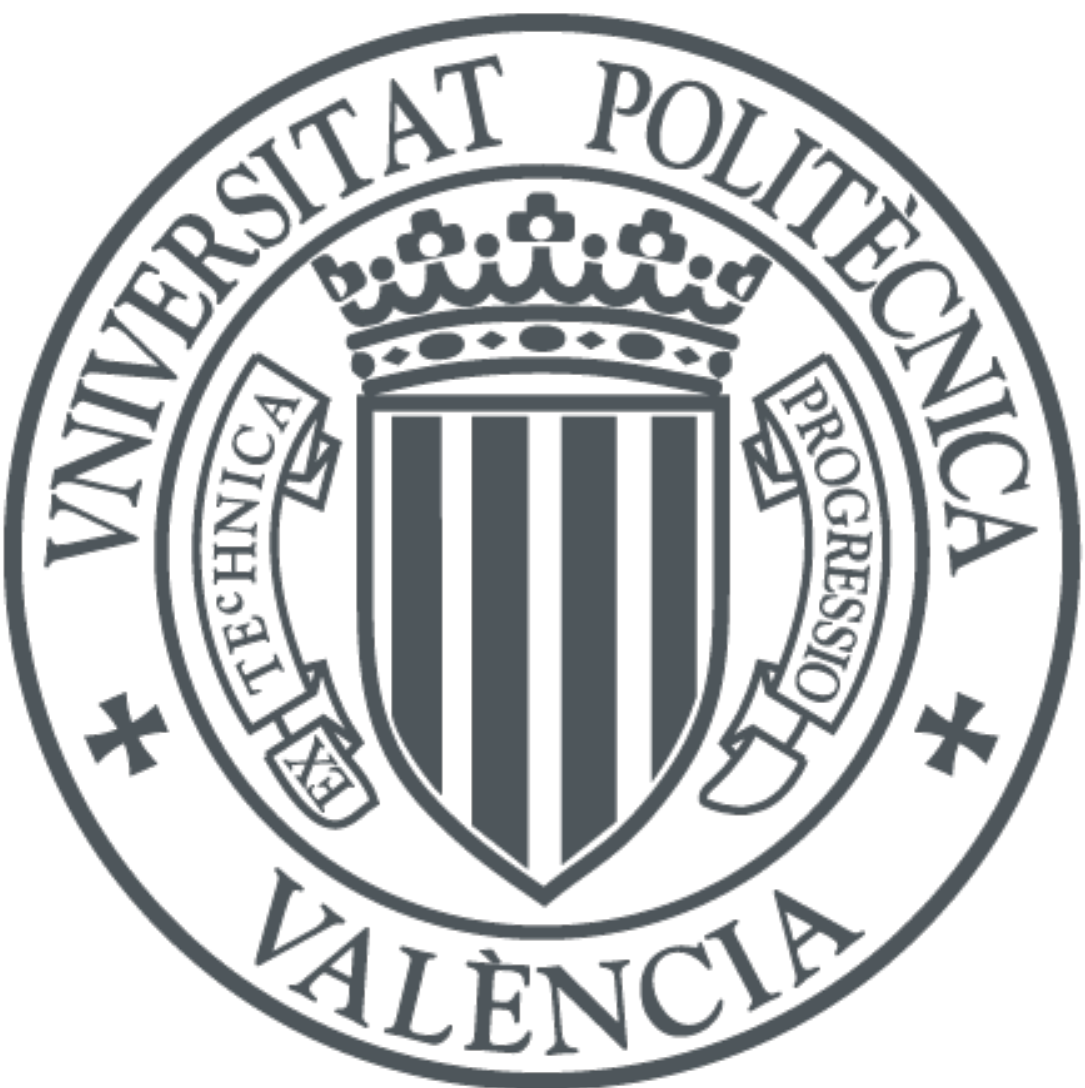

The final publication is available at

http://dx.doi.org/10.1002/app.41161/full

Copyright Wiley-Blackwell

Additional Information 


\title{
Influence of biodegradable materials in the recycled polystyrene
}

\author{
Samper M.D.*, Arrieta M.P., Ferrándiz S., López J. \\ Instituto de Tecnología de Materiales (ITM), \\ Universidad Politécnica de Valencia (UPV), \\ Plaza Ferrándiz y Carbonell s/n, 03801, Alcoy, Alicante, Spain \\ *e-mail: masammad@upvnet.upv.es
}

\section{ABSTRACT}

Polystyrene (PS) is one of the commonly used polymer in food packaging, that is why it generates a large amount of residue PS: Due to the need of reduce environmental damage that occurs, it is common recycle this polymer.

Recycling of PS may be affected by the introduction of biodegradable polymer in industrial food. For this reason we have studied the influence that generates small amounts of biodegradable polymer (PLA, PHB and TPS) in the recycled PS properties. The recycled PS and biodegradables polymers blends were evaluated by measuring the VST, MFI, FTIR and mechanical properties.

KEY WORDS: Polystyrene, biodegradable polymers, recycled polymers.

\section{INTRODUCTION}

Polystyrene (PS) is one of the most produced and consumed polymers in the world. It is a thermoplastic with good processing properties that is utilized for many plastics commodities because of their large availability at low cost. Therefore, PS is known as one of "packaging plastics" since it is widely used in different short-term applications. Despite the increasing attention for biodegradable polymers for food packaging sector, PS and others polyolefins are still the most common polymers used 
for this propose. As a result, enormous PS consumption from food packaging has led to a generation of huge amount of plastic waste. The treatment of this sort of waste has captured researchers' and industries attention during the last two decades ${ }^{1-4}$, due to the need of reduce the environmental damage. In order to reduce the accumulation of plastics waste, one commonly being used practice is to recycle them.

On the other hand, the increasing proactive attitude towards a reduction on the environmental impact promotes the used of biodegradable polymers for food industry as a replacement of petrochemical plastics ${ }^{5-7}$. In this sense, there are some biodegradable polymers that are gaining place in food packaging industries such as poly(lactic acid) $\mathrm{PLA}^{8,9}$, poly(hydroxybutyrate) $\mathrm{PHB}^{10}$; and thermoplastic starch, TPS ${ }^{11}$ since they could be disintegrated under composting conditions in just about one month $8,10,11$.

Adding biodegradable materials into the packaging market chain imply another nature of plastic disposal that have to be managed. Due to the low knowledge of consumers about where they have to throw away these new biodegradable materials after their use, they are commonly disposed with traditional packaging plastics. Although, biodegradable plastic products can also be recycled after their uses by traditional recycling ways ${ }^{12}$.

To obtain productive recycling process from mixtures of different polymeric materials derived from plastic waste, it is necessary first separate them according to their types ${ }^{13}$. However, the separation processes of the different plastics during recycling can be very complex and expensive, therefore the presence of some impurities from other different plastics are common in the polymeric recycled materials 14. The presence of others polymeric fractions in recycled plastics influences the structure and mechanical properties of the recycled products ${ }^{15}$. Assuming continuous high grow of biodegradable plastic market, it will be more and more common to find low amount of biodegradables materials in recycled plastics. It is known that mixtures of 
different types of polymers often derby in a loss of the mechanical properties ${ }^{16}$ and causes a diminution in the thermal stability ${ }^{1}$.

In this work recycled PS and biodegradables polymers blends were studied in order to simulate a recycled PS contaminated with low amount of biodegradable materials. Three different biodegradables materials were used at different percentage. The influence of each biodegradable material in PS thermal properties was evaluated at five different concentrations of biodegradable materials by using Vicat Softening Temperature (VST) and Melt Flow Index (MFI). Extruded blends followed by an injection molding process where prepared in dog-bond bars. The thermal stability requirements were evaluated by measuring the Vicat Softening Temperature (VST). In order to know the influence of different amount of biodegrade sample on the mechanical properties of PS, tensile test were carried out. While Fourier transformed infrared spectroscopy (FTIR) and Scanning Electron Microscopy (SEM) were used to evaluate the structural and surface properties. The disintegration under composting conditions was monitored to obtain a prospective approach on the degradation of blends system based on biodegradables materials incorporated into PS matrix.

\section{EXPERIMENTAL}

\section{Materials and sample preparation}

Polystyrene (PS) scrap were provided by ACTECO S.A. (Ibi, Spain) coming from food packaging.

PLA 4032D was supplied by NatureWorks LLC (USA), PHB P226 was provided by Biomer (Krailling, Germany) and TPS Mater Bi was supplied by Novamont (Novara, Italy).

Blending of PS with biodegradable polymers was carried out using a screw extruder (Dupra S.L., Castalla, Spain) at $30 \mathrm{rpm}$ rotor speed with a temperature of $180-200^{\circ} \mathrm{C}$. The blending were prepared by varying the biodegradable polymers contents, from 0 to $15 \%(0,2.5,5,7.5,10$ and $15 \%)$ (wt\%). Later samples for different mechanical tests 
were prepared by an injection molding process on a Babyplast standard 6/6 (Cronoplanst S.L., Abrera, Spain). We used a mold with normalized sample dimensions for tensile test according ISO-527.

\section{Mechanical properties}

The mechanical characterization was carried out using tensile and hardness tests.

The tensile tests were carried out using a universal ELIB 30 (S.A.E Ibertest, Madrid, Spain) following ISO-527. All the tests were carried out at room temperature at a speed of $10 \mathrm{~mm} \mathrm{~min}^{-1}$ and with a load cell of $5 \mathrm{KN}$. At least five test pieces of each samples were used.

The hardness tests were carried out using a Shore D Durometer, as indicated in the norm UNE-EN ISO 868. The equipment used was a mod. 673-D Durometer (Instrumentos J. Bot S.A., Barcelona, Spain) using samples of $4 \mathrm{~mm}$ thickness. A minimum of five measurements were taken and the average values were calculated.

\section{Infrared spectroscopy (FTIR) analysis}

Fourier transformed infrared spectroscopy (FTIR) measurement were carried out using Perkin-Elmer Spectrum BX infrared spectrometer (Perkin-Elmer España S.L., Madrid, Spain). For its completion, films with sufficient transparency were obtained through dissolution with trichloroethylene and subsequently dried to remove all solvent traces. Hundred scans at a resolution of $4 \mathrm{~cm}^{-1}$ were carried out for each sample.

\section{Scanning electron microscopy analysis}

The images obtained by SEM microscopy were performed with a Phenom (FEI company, Eindhoven, Nederland), using voltage $5 \mathrm{kV}$. The samples were previously covered with a layer of gold.

\section{Disintegration under composting conditions}


The mature compost was obtained from Mantillo. The compost had the following basic properties: organic solids $45 \%$; vegetable solids $40 \%, 30 \%$ of humidity and $\mathrm{pH}$ between 6 and 7 . Test dog-bon of the highest amount of biodegradable material (15\%) were buried into a compost reactor $(28 \mathrm{~cm} \times 19 \mathrm{~cm} \times 12 \mathrm{~cm})$ containing compost medium with a water content of around $50 \%$. Samples were recovered at 8 , 21 and 30 days.

After each extraction, a visual check and SEM images of the samples were carried out to study the degree of physical degradation in compost as a function of time. Thermogravimetric Analysis (TGA) tests were also done by using a TGA/SDTA 851 Mettler Toledo thermal analyzer (Schwarzenbach, Switzerland). Samples were weight around $10 \mathrm{mg}$ and heated from 30 to $600 \stackrel{\circ}{\circ}$ at $10 \stackrel{\circ}{\circ} / \mathrm{min}$ under air conditions.

\section{$\underline{\text { Other techniques }}$}

MFI measurements were obtained with an extrusion plastometer (AtsFaarS.p.A, Vignate, Italy) according to the guidelines of ISO-1133, the temperature and load used were $200^{\circ} \mathrm{C}$ and $5 \mathrm{~kg}$ respectively. And Vicat softening temperature (VST) measurements were made on a standard Vicat/HDT station DEFLEX 687-A2 (Metrotec S.A., San Sebastian, Spain) following ISO-306.

\section{RESULTS AND DISCUSSION}

\section{Detection of biodegradable materials in recycled PS by FTIR}

The FTIR technique provides a simple method for the detection of biodegradable materials in PS because the infrared spectra of the PLA, PHB and TPS have different characteristic bands of PS. As shown in figure 1 between 1790 and $1750 \mathrm{~cm}-1$ the blends PS/biodegradable materials (with $15 \%$ wt biodegradable material) exhibit a strong band that has not pure PS, this band is due to $C=O$ carbonyl stretching of PLA ${ }^{17}$ and $\mathrm{PHB}{ }^{18}$ and plasticizers used to obtain the TPS ${ }^{19-21}$. 


\section{Figure 1}

\section{Miscibility of PS/biodegradable polymers}

According to the chemical nature of polymers, these may be more or less miscible with each other. In general, semi-crystalline polymers and amorphous show incompatibility in the final mixture ${ }^{16,22}$. These incompatibilities may generate a lamination of material and loss of mechanical properties. Furthermore, the incompatibility also depends on the percentage of impurities present, the percentage of each polymer in the mixture, the percentage of crystallinity or the polarity of the components.

The relative affinity of two polymers can be estimated using the solubility parameters (ठ) ${ }^{23}$. Thus, the proximity of both polymers parameters used to evaluate the miscibility between them. To be considered components of the mixture compatible, the solubility parameters of the polymers should be of the same order.

Several methods have been developed for the determination of the solubility parameter, however it is generally calculated from the structural formula, due to its simplicity and the validity of the results obtained. Considering various types of simple molecules, Small made a list of molar attraction constants $(F)$ for several molecules ${ }^{24}$, which are additive. Thus, $\delta$ can be calculated by adding the molar attraction constants, considering the contribution that each group makes the overall structure of the molecule (Equation 1).

$\delta=\frac{\rho \sum_{j} F_{j}}{\mathrm{M}_{\mathrm{n}}}$ (Equation 1)

where $\rho$ is the density of the polymer, $M_{n}$ is the molar mass of the repeating unit, and $\sum_{\mathrm{j}} \mathrm{F}_{\mathrm{j}}$ is the sum of the group contributions to the cohesive energy density. 
The values of molar attraction constants $(F)$ of functional groups at $25^{\circ} \mathrm{C}$ are shown in table 1 . Small used to calculate the solubility parameter.

\section{Table 1.}

The results of calculation of $\delta$ according to the method Small, using equation 1 and Table 1 can be seen in Table 2 .

The results of $\delta$, according Small method, using equation 1 and Table 1 can be seen in Table 2. It can be seen that $\delta \mathrm{PS}$ is $18.5 \mathrm{MPa}^{1 / 2}$ and that none of biodegradable materials presents similar $\delta$, although the PLA is the biodegradable material having the nearest $\delta 19.4-20.1 \mathrm{MPa}^{1 / 2}$ to PS and the TPS is the material with the least close to $\delta$ PS (8.4 $\left.\mathrm{MPa}^{1 / 2}\right)$, are therefore expected to biodegradable materials studied are not miscible with the PS and small amounts of biodegradable materials produced a decrease in the mechanical properties of the recycled material. Also as can be seen in the SEM images taken with PS15PLA samples (figure 2.a), PS15PHB (figure 2.b) and PS15TPS (figure 2.c) clearly shows phase separation of the blends, symptom evident of the immiscibility of the components of the blends. When two polymers that form a blend are immiscible, a biphasic system is formed. One of them acts like matrix phase and the other acts like dispersed phase. In general, these materials have poor mechanical properties, because the adhesion between the phases is not good and stress concentrations areas are generated ${ }^{25-27}$.

\section{Table 2}

Figure 2

\section{Mechanical characterization}


The analysis of the mechanical properties of the blends includes different parameters, such as tensile strength, elongation at break and the energy under stress-strain curve (toughness modulus).

Compatibility between the two polymers of the blend is a major factor that affects the performance of the material; if the polymers are incompatible, a general alteration in the mechanical properties of the blend can be observed. Incompatibility causes important negative effects on the properties of the material ${ }^{28}$.

Figure 3 shows the evolution of the tensile strength considering the composition of all blends. It can be seen that the addition of PLA does not vary significantly this property because practically remains constant in all formulations. However it can be seen that the incorporation of PHB and TPS in the PS causes a decrease of the tensile strength, more pronounced in the case of the PHB. This decrease is due to the lack of interaction between the interface of the components of the blend as discussed above.

Figure 3

The graphical representation of the elongation at break also shows decreased this property with increasing the content of biodegradable material. The elongation at break of the samples with low content of biodegradable material (2.5 - $7.5 \mathrm{wt} \%)$ decreases slightly, but high concentrations of biodegradable material content $(10,15 w t \%)$ induce to a sharp decrease in elongation, sharper in the case of PS-TPS samples with a decrease of the elongation at break of $90 \%$ (figure 4 ).

Figure 4.

As expected also the toughness modulus decreases as the content of biodegradable polymer. Figure 5 shows a comparison of the blends and it can be appreciated that the PS-PLA blend is least this property decreases. 


\section{Figure 5}

As we have seen the mechanical properties of the blends decrease with increasing the percentage of biodegradable material. It is one of the symptoms of the immiscibility of the components. It was also detected that the PLA is biodegradable material less decreases the mechanical properties of PS, this phenomenon can be explained by the proximity of $\delta$ of PLA and PS.

\section{Thermal properties}

In the previous sections we have described changes in mechanical properties caused by the presence of biodegradable polymers, but it is not the only important property that may affect the recycling of materials. Another important effect is the possible alteration of the melt flow index (MFI) of the blends, since this property is very important for processing the material ${ }^{29}$.

The graphical representation of the results (figure 6) shows that the MFI increases as the biodegradable polymer content increases. Can also be seen that PHB is the biodegradable polymer more increases MFI the PS. This result could be related with some levels of PHB degradation. PHB has a small processing window for melt extrusion by reason of its melting point is approximately at $180{ }^{\circ} \mathrm{C}$ while the degradation temperature is typically around $270{ }^{\circ} \mathrm{C}{ }^{30}$. Thus, at the processing temperature used for PS processing, in the range of $180-200{ }^{\circ} \mathrm{C}$, somewhat $\mathrm{PHB}$ thermal degradation takes place. Meanwhile, the PLA is less than change the MFI of PS. This behavior is very similar to the mechanical properties of the blends.

\section{Figure 6}


The thermal stability of blends of PS with biodegradable polymers was determined by the Vicat softening temperature (VST). The results for all blends tested (figure 7) show a linear correspondence between the VST and blend composition. Systems PS / biodegradable polymers reduce the VST with increasing concentration of biodegradable polymer. This behavior can be attributed to the strong macroscopic nature with respect to temperature VST and other qualities like mechanical properties, in which the levels of interaction between the interface of the integral components of the blend plays a decisive role.

\section{Figure 7}

\section{Disintegration under composting conditions}

Macroscopic observations of the recovered samples after 8, 21 and 30 days of exposure to composting conditions are shown in figure 8. All samples suffered physical changes after 21 days because of the physical disintegration of biodegradables materials. All samples presented a surface deformation after 30 days. Also SEM images showed somewhat changes in the samples surfaces (figure 8).

\section{Figure 8}

Macroscopic observations were confirmed with TGA tests. TGA results showed that in PS samples added with PLA and PHB the decomposition steps have been resolved into the different components which the first one can be assigned to the loss of the biodegradable material, PLA and PHB, and the second step is the degradation of PS itself. In the case of TPS the degradation occurred in only one step. It was clear noticeable that the initial degradation temperature was shift toward lower temperatures (figure 9 a, c and d) as degradation time increased for all studied formulations. PSTPS15\% samples also showed that the maximum degradation temperature was shifted 
to higher temperatures after the compost exposition due to the lesser amount of TPS in the formulation leading to less contaminated PS with higher thermal stability. These results showed that all biodegradable material content decreased after their expose to compost. It have been reported that neat PLA and TPS are disintegrated under composting conditions in $25-30$ days ${ }^{8,10}$. Meanwhile, PHB need more time to be disintegrated in compost (approximately 45 days) ${ }^{10}$. However, in the present work there was remained biodegradable material in each sample after the 30 days in compost, showing that PS presence delay de disintegration of biodegradable materials. It is known that polymers disintegration in composting material starts by a hydrolysis reaction ${ }^{31}$. In this case the molecular interactions between biodegradable materials and PS could prevent biodegradable materials from water; therefore the action of microorganisms is delayed.

\section{Figure 9}

\section{CONCLUSION}

In this work we have evaluated mechanical and thermal properties of blends made with recycled PS and different biodegradable polymers (-PLA-, PHB and TPS-)-.

The presence of low percentages of the biodegradable polymers in the recycling of PS cause significant losses in mechanical properties and thermal properties (Vicat-, IMF)-. The decrease of these properties is a clear indication of immiscibility between the components, this effect is also visible in the SEM images of fractured specimens. Besides incorporating biodegradable polymers in the recycled PS can cause partial biodegradation of the material if given the right conditions.

Therefore it is essential to detect the biodegradable materials recycling PS for possible elimination of the production chain. The detection of these materials is relatively simple when using FTIR equipment because biodegradable polymers exhibit a strong band between $1790-1750 \mathrm{~cm}^{-1}$. 


\section{REFERENCES}

1. D. Garcia, R. Balart, J. E. Crespoand J. Lopez, Journal of Applied Polymer Science, 101, 2464-2471 (2006).

2. D. Garcia, R. Balart, F. Parresand J. Lopez, Journal of Applied Polymer Science, 106, 20-27 (2007).

3. F. Parres, L. Sanchez, R. Balartand J. Lopez, Journal of Analytical and Applied Pyrolysis, 78, 250-256 (2007).

4. M. D. Samper, D. Garcia-Sanoguera, F. Parresand J. Lopez, Progress in Rubber Plastics and Recycling Technology, 26, 83-92 (2010).

5. M. P. Arrieta, M. A. Peltzer, M. d. C. Garrigósand A. Jiménez, Journal of Food Engineering, 114, 486-494 (2012).

6. J. A. Colwill, E. I. Wrightand S. Rahimifard, Journal of Polymers and the Environment, 20, 1112-1123 (2012).

7. M. lotti, P. Fabbri, M. Messori, F. Pilatiand P. Fava, Journal of Polymers and the Environment, 17, 10-19 (2009).

8. E. Fortunati, I. Armentano, A. lannoni, M. Barbale, S. Zaccheo, M. Scavone, L. Visaiand J. M. Kenny, Journal of Applied Polymer Science, 124, 87-98 (2012).

9. M. P. Arrieta, J. López, A. Hernándezand E. Rayón, European Polymer Journal, 50, 255-270 (2013).

10. M. Rutkowska, K. Krasowska, A. Heimowska, G. Adamus, M. Sobota, M. Musiol, H. Janeczek, W. Sikorska, A. Krzan, E. Zagarand M. Kowalczuk, Journal of Polymers and the Environment, 16, 183-191 (2008).

11. Y.-L. Du, Y. Cao, F. Lu, F. Li, Y. Cao, X.-L. Wangand Y.-Z. Wang, Polymer Testing, 27, 924-930 (2008).

12. M. P. Arrieta, F. J. Parres-García, J. López-Martínez, R. Navarro-Vidaland S. Ferrándiz, Pirólisis de residuos de bioplásticos: Productos obtenidos del ácido poliláctico (PLA), 87, 395399 (2012).

13. A. Kanand R. Demirboga, Journal of Materials Processing Technology, 209, 2994-3000 (2009).

14. R. Balart, J. Lopez, D. Garciaand M. D. Salvador, European Polymer Journal, 41, 21502160 (2005).

15. F. Vilaplanaand S. Karlsson, Macromolecular Materials and Engineering, 293, 274297 (2008).

16. R. Navarro, S. Ferrandiz, J. Lopezand V. J. Segui, Journal of Materials Processing Technology, 195, 110-116 (2008).

17. Q. X. Gong, L. Q. Wangand K. H. Tu, Carbohydrate Polymers, 64, 501-509 (2006).

18. T. Furukawa, H. Sato, R. Murakami, J. M. Zhang, Y. X. Duan, I. Noda, S. Ochiaiand Y. Ozaki, Macromolecules, 38, 6445-6454 (2005).

19. H. G. Dai, P. R. Chang, J. G. Yu, X. F. Maand P. Zhou, Polymer Engineering and Science, 50, 970-977 (2010).

20. P. Ekabutr, W. Lerdwijitjarudand A. Sittattrakul, Polymer Engineering and Science, 53, 134-145 (2013).

21. X. F. Ma, P. R. Chang, J. G. Yuand M. Stumborg, Carbohydrate Polymers, 75, 1-8 (2009).

22. S. Ferrandiz, M. P. Arrieta, M. D. Samperand J. López, Journal of Optoelectronics and Advanced Materials, 15, 5 (2013).

23. K. Odelius, M. Ohlson, A. Hoglundand A. C. Albertsson, Journal of Applied Polymer Science, 127, 27-33 (2013).

24. B. A. Miller-Chouand J. L. Koenig, Progress in Polymer Science, 28, 1223-1270 (2003). 
25. P. G. Ghodgaonkarand U. Sundararaj, Polymer Engineering and Science, 36, 16561665 (1996).

26. H. Shariatpanahi, H. Nazokdastand M. Hemmati, Journal of Elastomers and Plastics, 35, 115-131 (2003).

27. R. Balart, D. García-Sanogueraand J. López, Caracterització de polímers, 2005.

28. E. Fekete, E. Foldesand M. Pukanszky, European Polymer Journal, 41, 727-736 (2005).

29. F. Parres, R. Balart, J. Lopezand D. Garcia, Journal of Materials Science, 43, 3203-3209 (2008).

30. M. P. Arrieta, E. Fortunati, F. Dominici, E. Rayón, J. Lópezand J. M. Kenny, Carbohydrate Polymers, 107, 16-24 (2014).

31. G. Kale, R. Auras, S. P. Singhand R. Narayan, Polymer Testing, 26, 1049-1061 (2007).

\section{TABLES}

Table 1. Small's molar attraction constants for several functional groups.

Table 2. Values of the solubility parameters calculated from those constants in table 1. 


\section{FIGURES}

Figura 1. FTIR spectra: PS and PS/biodegradable materials blends

Figura 2. SEM image at $x 2000$ magnification of the samples, a) PS15PLA; b) PS15PHB; y c) PS15TPS

Figura 3. Variation of tensile strength versus biodegradable polymers wt \% incorporated to PS.

Figura 4. Variation of strain at break versus biodegradable polymers wt \% incorporated to PS.

Figura 5. Variation of toughness modulus versus biodegradable polymers wt $\%$ incorporated to PS.

Figura 6. Plot of MFI index versus different biodegradable polymers wt\%.

Figura 7. Plot of VST temperature versus different biodegradable polymerswt\%.

Figura 8. PS-TPS15\%, PS-PLA15\% and PS-PHB15\% composites after 8, 21 and 30 days exposed to a composting conditions at $58^{\circ} \mathrm{C}$.

Figura 9. TGA graphs of blends composites after 8,21 and 30 days exposed to a composting conditions $\left(T=58^{\circ} \mathrm{C}\right)$, a) TGA curves of PS-TPS composites, b) DTG curves of PS-TPS composites, c) TGA curves of PS-PLA composites and d) TGA curves of PS-PHB. 